\title{
ANTISYMMETRY AND JAPANESE
}

\author{
RICHARD S. KAYNE \\ New York University
}

\begin{abstract}
This paper focusses on certain aspects of the antisymmetry hypothesis of Kayne (1994) and their implications for Japanese. The relation between S-H-C and the question of OV/VO order is discussed. The solidity of the antisymmetry hypothesis is enhanced by some previously undiscussed cross-linguistic gaps, i.e. imaginable language types that appear never to occur. Adpositions are cross-linguistically paired with a Khead; DP-movement to Spec, $\mathrm{K}$ and VP-movement to Spec, $\mathrm{P} / \mathrm{P}^{\prime}$ cut across prepositional and postpositional languages, in a way different from Kayne (1994). Complementizers are treated briefly.*
\end{abstract}

Keywords: antisymmetry, Japanese, preposition, postposition, complementizer

\section{Introduction}

In this paper, I would like to focus on certain aspects of the antisymmetry hypothesis of Kayne (1994) and to a certain extent on their implications for Japanese. I will take as a starting point my hypothesis that syntactic structure is universally and without exception of the form S-H-C. The complement of a head invariably follows that head. The associated specifier invariably precedes both head and complement.

This S-H-C hypothesis is to be taken to hold at all stages of a derivation, both prior to movement and subsequent to movement. (There is no sense in which it is a hypothesis about 'base' structure alone, contrary to the occasional misunderstanding.)

* This paper originated as a plenary talk presented on November 15, 2002 in Tokyo to the 20th anniversary meeting of the English Linguistic Society of Japan. I am indebted to Larisa Avram, who generously lent me the use of her NIAS office while she was away, and thereby greatly facilitated the writing of this paper. 
Given this, the relation between S-H-C and the question of OV/VO order cannot be a simple one. ${ }^{1}$ If an object can occupy the Spec of its own V (whether as the result of movement or, thinking of Larson (1988) and Barbiers (2000a), because it is generated/merged there), then it will precede that $\mathrm{V}$. If an object can remain in the complement position of its own $\mathrm{V}$, then it will follow that $\mathrm{V}$. If an object of $\mathrm{V}$ ends up in the Spec position of a head that is itself higher than $\mathrm{V}$, then that object will precede V. If what we think of as an object of $\mathrm{V}$ ends up in the Spec position of a head lower than the position in which $\mathrm{V}$ itself ends up, then that object will follow $\mathrm{V}$.

It follows that the OV order of a language like Japanese directly excludes the possibility that the object in Japanese has remained in the complement position of V. It must rather be in (or within) a Spec position, perhaps that of $\mathrm{V}$ itself, but much more likely that of some head higher than $\mathrm{V}$. I return to this question shortly.

In Kayne (1994) I argued that specifiers are instances of phrasal adjunction. I continue to adopt here the position that syntax does not require a notion of phrasal adjunction distinct from the notion of specifier. Related to this was the claim that there cannot be multiple specifiers for a single head. I will maintain this claim, too. (For corroborating argument, see Rizzi (1997) and Cinque (1999). ${ }^{2}$ )

The S-H-C hypothesis (combined with the unavailability of adjunction as distinct from specifier and with the ban on lowering operations) leads to the conclusion that there can be no rightward movement operations in any language, as I will continue to hold.

In what follows, I will address some specific questions of Japanese syntax (as well as some more general considerations of syntactic theory). Whatever the subarea of Japanese syntax that one might be interested in, the question will arise as to whether or not one's analysis

1 The terms OV and VO are informal ones that leave hidden all sorts of subdistinctions. On VO, for example, see Pollock (1989) and Pearson (2000).

2 Also Kayne (to appear - a) on the idea that UG imposes a maximum of one interpretable syntactic feature per lexical item.

Apart from the question of multiple specifiers and adjunction, the S-H-C hypothesis translates straightforwardly into Chomsky's (1995:245) terms, where complement corresponds to 'first merged' (which must for me follow the head) and specifier to 'second merged' (which must precede the head). 
needs to be compatible with antisymmetry. If antisymmetry is not a valid characterization of $\mathrm{UG}$, then the answer is no. If antisymmetry does constitute a valid characterization of UG, then the answer is yes.

Evaluation of the antisymmetry hypothesis must ultimately rest on evidence from as many languages as possible, in as many areas of syntax as possible. One must test to whatever extent possible the antisymmetry predictions concerning language 'gaps,' i.e. the claim that certain types of languages, though easily imaginable (such as 'reverse German'3), will never be found. One must in some cases compare earlier analyses based on rightward movement with alternatives favored or imposed by antisymmetry, often making in exchange more extensive use of leftward movements (as discussed in part below). One must ask how antisymmetry (as opposed to a theory of syntax lacking it) interacts with other general properties of UG. ${ }^{4}$

Since this evaluation will be potentially sensitive to evidence from any language, it is clear (but not surprising) that the question whether analyses of Japanese need to respect antisymmetry cannot be answered solely by looking at aspects of Japanese syntax. Evidence bearing on Japanese need not, to put it another way, come only from Japanese.

\section{Japanese}

\subsection{The Position of Objects}

It is uncontroversial to say that objects in Japanese can be found outside VP, in a higher Spec position, as in sentences whose derivation involves what we informally call scrambling. The question is whether Japanese objects ever surface within VP, in complement position of V (or in some Spec position lower than V). Antisymmetry says not,

3 See Kayne (1994: 50).

4 A further question concerning antisymmetry arises within Chomsky's recent minimalist perspective. More specifically, the question is whether or not antisymmetry (assuming it to be correct) constitutes an imperfection of the language faculty in Chomsky's technical sense. Chomsky (2001b) thinks that it would. Although I will not pursue this here, it might alternatively be the case that our initial intuitions about perfection vs. imperfection (in this technical sense) are not fully reliable. (For example, syntactic antisymmetry might be inherited from a parallel property of phonology.) 
given $\mathrm{OV}$ order.

We can set aside potential cases of incorporation as not directly relevant, since incorporation by definition involves movement out of complement position. The standard view is that incorporated objects adjoin to V, as in Baker (1988). Since antisymmetry leads to the expectation that such head-to-head adjunction will be left-adjunction, ${ }^{5}$ the resulting OV order would be perfectly straightforward.

The plausibility of the claim that objects in Japanese are invariably found in (or within) a position higher than $\mathrm{V}$ is enhanced by the observation that in some OV languages objects move higher than $\mathrm{V}$ in a very visible way. ${ }^{6}$ One such case is Malayalam, in which objects must surface in a position preceding that of VP-external focus (SOFocV), as emphasized by Jayaseelan (2001). Another is that of the continental West Germanic languages (if we abstract away from V-2 contexts). In West Flemish, for example, objects precede one of the negation markers (see Haegeman (2001; to appear)). In Dutch and German, that type of (clitic) negation is not present, but the infinitive marker must still intervene between object and verb $(\mathrm{O} t e / z u$ $\mathrm{V}_{\text {infin }}$ ) and so must what are called separable particles, in the order ' $\mathrm{O}$ Prt $t e / z u \mathrm{~V}_{\text {infin }}$, for example, in German: ${ }^{7}$

(1) ... das Buch mitzubringen. ('...the book with/along-to-bring' $=$ 'to bring along the book')

The above point about West Flemish negation is made in a more general way by Whitman (to appear). Using earlier typological work

5 See Kayne (1994: 38).

I agree with Baker that what is called noun-incorporation involves movement. It is somewhat less clear that adjunction to a head is involved (as opposed to movement to a low Spec position). Noun-incorporation as adjunction to a head would not lead one to expect the following conjecture to be correct:

(i) NV incorporation (with that order) is never found in V-initial languages. Whether (i) is correct needs to be looked into. Relevant to the whole question is Hoekstra (1999).

$6 \mathrm{Cf}$. the fact that in German when an adjectival complement is preposed it must precede material like 'completely,' as noted by van Riemsdijk (1983: 229; 1992: 503); see also Svenonius (1992: 112).

7 As so often, the orthography, in writing mitzubringen as one word, is, while perhaps reflecting something important about the phonology, not being faithful to the syntax — see Myers (1987) and Julien (2002). 
by Dahl (1979) and Dryer (1988; 1992), Whitman notes the importance of the existence of a substantial set of 'SONegV' languages, i.e. languages in which the normal position of negation is between object and following verb. As he shows, they strongly suggest obligatory leftward movement of the object past negation.

On the basis of these considerations, the antisymmetry claim that Japanese objects must end up in or within a position asymmetrically ccommanding $\mathrm{V}$ is not very radical. ${ }^{8}$

\subsection{Relative Pronouns}

A rather different area of syntax where one sees antisymmetry impinge on Japanese is that of relative pronouns. Of course, Japanese does not have any. But that is precisely the point, insofar as it is possible to find an antisymmetric account of their absence.

In Kayne (1994: 95) I proposed that the general absence of relative pronouns in prenominal relatives can be understood in terms of the fact that prenominal relatives necessarily involve movement of the relative clause from an earlier postnominal position. ${ }^{9}$ (Japanese is a particular instance of this generalization.) I won't repeat the details here, but will note the following.

Kornfilt (2000) has recently studied the apparently curious phenomenon whereby certain Central Asian Turkic languages have an Agr morpheme associated with their (prenominal) relative clauses that agrees with the subject of the relative. The curious thing is that this Agr follows the 'head' of the prenominal relative clause. (Thus one has 'Rel N Agr' (more exactly ' $\left[\mathrm{S}_{\mathrm{i}} \mathrm{OV}\right] \mathrm{N} \mathrm{Agr}_{\mathrm{i}}$ '), where Rel is the relative clause, $\mathrm{N}$ is the 'head' of the relative and Agr is what matches features with the subject contained within the relative.) Kornfilt's proposal is that this apparently nonlocal agreement reflects the stranding of an Agr clitic (that originally occupied a high position within the (originally postnominal) relative) under leftward movement of the relative

8 Whitman argues that the object is actually carried along by remnant VP-movement, in which case 'within' would be appropriate. The question whether the object in $\mathrm{OV}$ sentences moves out of complement position by itself or is carried along as part of a larger phrase arises in all the cases discussed - see especially Haegeman $(2000 ; 2001)$.

9 For a partially different view on Japanese, v. Murasugi (2000). 
clause past the 'head.' (That is, ' $\left[\mathrm{S}_{\mathrm{i}} \mathrm{OV}\right] \mathrm{N}$ Agr' ${ }^{\prime}$ derives from ' $\mathrm{N}$ [ $\mathrm{Agr}_{\mathrm{i}}$ $\left.\left.\left[\mathrm{S}_{\mathrm{i}} \mathrm{OV}\right]\right] .{ }^{\prime}\right)^{10}$

Kornfilt's proposal, which supports the idea that prenominal relatives originate postnominally, ${ }^{11}$ makes sense of what at first looks like 'misplaced' agreement. A natural antisymmetric conjecture at this point (assuming restrictions on phrasal movement of Agr that I won't try to spell out here) would be:

(2) There is no mirror-image of Central Asian Turkic, i.e. no language has a prenominal Agr that agrees with the subject contained within a postnominal relative.

A prenominal Agr (contrary to the postnominal Agr discussed by Kornfilt) could not have been stranded by relative IP movement, since that movement would have had to be rightward, which is impossible. ${ }^{12}$

Arguably similar to the Turkic phenomenon Kornfilt discusses is the fact that the Finnish possessive suffix (v. Branch (1987: 606)) follows the (oblique) Case marker ('XP K Poss'), where Poss seems to 'belong to' XP. ${ }^{13}$ In the spirit of Kornfilt's proposal, this may originate as ' $\mathrm{K}$

10 I have simplified a bit by omitting consideration of $\mathrm{D}$ and of the fact that the relative IP moves to Spec, D. I have also abstracted away from the fact that the 'head' N itself is moved leftward from within the relative - v. Kayne (1994: 87).

The genitive Case that appears on these subjects in some Turkic languages should be compared to the Hungarian possessive dative discussed by Szabolcsi (1983; 1994).

The high Agr within the (originally postnominal) relative recalls the complementizer agreement (i.e. the presence of an Agr immediately following the complementizer and matching features with the following subject) found in some Germanic languages.

$11 \mathrm{Cf}$. the strong argument for leftward movement (of the relative itself, in Chinese) given by Simpson and Wu (2002a).

12 If (2) is correct, it raises a question for Chomsky's (2000) proposal to allow downward agreement (why could an Agr merged above $\mathrm{N}$ not agree with the subject DP within the relative?). This is somewhat similar to the potential problem he notes (Chomsky (2001a: note 38)) relative to Romance past participle agreement. (Note that movement is not a sufficient condition for such agreement, as shown by Italian interrogatives - v. Kayne (2000b: chaps. 2 and 3) and Déprez (1998: 39).) Downward agreement is argued against by Koopman (to appear) - cf. also Kayne and Pollock (2001: note 27).

13 Cf. perhaps the Armenian construction mentioned by Sigler (1997: 85); also the fact that when possessive agreement in Hopi is suffixal (in the third person, much as in Papago/'O'odham (Zepeda (1983: 76)) third singular) it both precedes and follows the Case ending-Jeanne (1978: 105, 107, 121, 125); also perhaps 
[Poss XP]' with XP moving across Poss and $\mathrm{K}$ (whether in one or two steps).

\subsection{Head-Finality}

It has often been noted that prenominal relative clauses of the Japanese sort are generally absent from VO languages (although for this to be strongly true (even apart from Chinese) one needs to set aside reduced subject-based relatives of the type found even in English a recently arrived letter). ${ }^{14}$ And it is sometimes thought that this supports a notion of 'head-finality' that languages like Japanese would display in a particularly consistent fashion.

In fact, I think that prenominal relatives pose a problem for any notion of consistent head-finality, since the supposed generalization rests on a double use of the term 'head'. If by 'head of a relative clause' we mean the material outside of the relative clause proper (but not counting higher determiner elements), then in the apples that John bought, apples is the head. The problem is that we also have the pound of apples that John bought, the allusion to his wife that John got upset at, etc., in which it looks like the head of the relative must then be pound of apples or allusion to his wife. But these are not heads (rather, they are phrases) in the sense in which V is a 'final head' in OV languages.

What this suggests, I suspect, is that although the (near-)exclusion of prenominal relatives in VO languages is something we want to find an explanation for, that explanation cannot reside in any notion of 'consistent head-finality.' This in turn is related, it seems to me, to a broader weakness in that notion, which has been based to a significant extent on the supposition that languages by and large pattern either as 'head-final' or as 'head-initial.' But that supposition looks highly questionable, as Kroch (2001:706) has pointed out, observing that most languages are actually inconsistent in head-directionality. I think that Kroch is correct, especially as one takes into account a wider range of heads than was taken into account at earlier stages of the theory.

Gwari having '...def. + neg' — v. Hyman and Magaji (1970: 120) — where 'def' is a post-relative determiner and 'neg' one marker of relative-internal negation.

14 On the English, see Kayne (1994: 99). 
When one broadens one's view away from just the lexical heads $\mathrm{N}, \mathrm{V}$ and $\mathrm{A}$ (and perhaps $\mathrm{P}$ ) to encompass complementizers of different sorts, question particles, topic and focus particles, and tense and aspect morphemes of various kinds, the inconsistency that Kroch points to becomes clear. ${ }^{15}$

In fact, it is very plausibly the case that Japanese itself is 'inconsistent,' in that its particles $w a$ and $g a$ are actually 'initial' heads. This proposal was made in Kayne (1994: 143) (based on an earlier similar proposal for Hungarian made by Brody $(1990)^{16}$ ) and has since been expanded on by Whitman (2001). The idea is that $w a$ and $g a$ are high functional heads in the sentential skeleton. $W a$, for example, may be a Top ${ }^{0}$ in Rizzi's (1997) sense, much as that discussed for Gungbe by Aboh (1999).

From an antisymmetric perspective, there is a natural reinterpretation of the notion 'final head,' which would be a head the entirety of whose complement has moved past it to a higher position or positions. A head that is not a 'final head' in this sense would be an 'initial head.' But there is no reason to think that 'final'/ 'initial' head is a primitive of syntactic theory, and no reason to think that languages must be consistent in having only one type. (In Kayne (1994: xv) I argued that no language could be uniformly head-final at all.)

\section{Additional Cross-Linguistic 'Gaps'}

\subsection{Serial Verbs}

Carstens (2002) has argued that serial verb constructions provide strong evidence for antisymmetry by showing cross-linguistic constancy of a surprising sort. Although the arguments of the verbs in question

15 Travis (1989) was perhaps the first to call attention to the importance of inconsistent' languages.

To mention just one little cited example, Western Shoshoni (Crum and Dayley (1993)) is an OV language with postpositions that has an initial if (p. 186), as well as various 2nd-pos. elements (that almost certainly reflect the presence of an 'initial' head) and postnominal relatives (that are non-finite).

See also Julien $(2002 ; 2003)$.

16 Cf. also Lecarme's $(1991 ; 1999)$ proposal that the focus marker in Somali is Ilike/C-like despite looking like a postposition. 
can occupy different positions relative to those verbs (p. 19), depending on the language, the relative order of the verbs themselves seems not to vary at all cross-linguistically. Moreover, the order found is what we would expect if syntax is uniformly (S-)H-C. Put another way, serial verb constructions appear to provide us with a window into UG in which we see universal $\mathrm{H}-\mathrm{C}$ order unobscured by verbal or verb phrase movements.

\subsection{Aux V vs. V Aux}

On the other hand, in non-serial-verb constructions, the relative order of verbs can vary substantially. For example, many languages have their auxiliaries preceding the main verb, many have the opposite order. (Some (perhaps many), like Dutch, show either order, depending on various factors.) Yet the two orders are clearly not symmetric to one another, ${ }^{17}$ as becomes rapidly apparent when one looks at their interaction with adverbs. 'Aux V' often allows intervening adverbs, as in English John has recently seen Mary, whereas 'V Aux' generally does not. ${ }^{18}$

Somewhat similarly, Dryer (1996: 1059) has noted that there are OV languages in which a subordinate $\mathrm{V}$ can follow a matrix verb like 'want' (i.e. languages in which the counterpart of ${ }^{*} J o h n$ wants to Paris (to) go is grammatical), but that there are no VO languages allowing a subordinate V to precede 'want' (i.e. no languages in which the counterpart of *John (to) go to Paris wants is grammatical). Put another way, although both '... want ... go ...' and '... go ... want ...' are commonly found, the two verbs can be separated by an argument of 'go' only in the former case. I will not pursue these questions here, other than to note that Koopman and Szabolcsi (2000) is very pertinent.

17 Although not closely related to the present discussion, there has also been a use of the term 'symmetric' to characterize the behavior of direct and indirect object in certain Bantu languages. Ngonyani (1996) has shown, though, that that symmetry breaks down with reflexives, at least in some of these apparently symmetric languages.

18 Adverbs must be kept apart from emphatics and morphemes corresponding to words like even, etc. 


\subsection{Adverbs and ('Heavy') Objects}

Another cross-linguistic gap (that would be unexpected under a symmetric view of syntax) is found in the positional interaction of adverbs and definite objects. As is well-known, there are VO languages (such as English) in which $\mathrm{V}$ and $\mathrm{O}$ cannot be separated by adverbs. (In English, when there is only one non-prepositional object, $\mathrm{V}$ and $\mathrm{O}$ can be separated by a particle - even that is not possible in Danish (also VO).) What seems to be unattested is an OV language that systematically forbids its adverbs from intervening between $\mathrm{O}$ and $\mathrm{V}$ (at least when $\mathrm{O}$ is definite). ${ }^{19}$

This point can be (informally) reformulated in terms of scrambling: An OV language will always allow (some) scrambling, at least with definites. That is not true of all VO languages. ${ }^{20}$ (Note, however, that to judge by Slavic some VO languages do allow (some) scrambling. ${ }^{21}$ ) Part of this almost follows immediately. Since in an OV language the object must, from the present perspective, have moved to some Spec position higher than $\mathrm{V},{ }^{22}$ it is natural to think that it can therefore also reach a Spec position higher than at least some adverbs (yielding ' $O$ Adv V'). Although a more precise account will have to be more specific about the character of the relevant landing sites, it is clear that in the absence of any possibility for rightward object movement (and right-adjoined positions for adverbs) there is no expectation that ' $\mathrm{V}$ Adv O' can be derived in parallel fashion. (For ways in which ' $\mathrm{V}$ Adv O' can be derived via leftward movement(s), see Pollock (1989) and Nilsen (2003).)

Rightward movement of an object was a standard tool of syntactic theory, in the guise of 'heavy-NP shift' (in languages like English), until Larson $(1988$; 1990) showed that it could be dispensed with. In his analysis, the 'heavy' NP remained in situ - his base structures plus leftward movement of a verbal projection accounted for the observed order. Den Dikken (1995) subsequently proposed that the heavy NP

19 This statement is not intended to extend to OVX languages like BambaraKoopman (1992) - that will be discussed below.

20 For relevant discussion, see Ogawa (2001).

21 Slavic was not taken into account in Saito and Fukui (1998).

22 There may well be no in situ (definite) objects - see Sportiche (2002) and related work of his. 
should itself be taken to move, too, though leftward. Adopting den Dikken's proposal, we can now think of heavy-NP shift as a subvariety of scrambling, the only kind that English has (if topicalization is distinct from scrambling).

From the conclusion that English has a limited variety of scrambling with heavy arguments it does not follow that all VO languages do. Put another way, VO languages do not automatically have heavy-NP shift. Examples of languages that do not are Haitian, Bambara and Chinese, according to Dejean (1993), Koopman (1992: 581) and Tang (1998: 132). Thus these languages admit leftward scrambling of objects even less than English does. (What the underlying parametric difference(s) is/are remains to be investigated. ${ }^{23}$ )

In analyzing heavy-NP shift as leftward movement of the object, den Dikken was led to propose, for (languages like) English, that such sentences also involve leftward VP-movement (to a position higher than the landing site of the object). ${ }^{24}$ Consider now English sentences like ${ }^{25}$

(3) All of a sudden, there hit the building a shell *? (fired by our own troops).

The fact that this kind of sentence is much more acceptable if the subject argument contains a (reduced) relative, plus the post-object position of that subject argument, suggests a close link with heavy-NP shift sentences. At the same time, as Chomsky (1995: 343) has noted, such

23 The lack of heavy-NP-Shift, at least in Haitian, may ultimately follow from the lack of relative clause 'extraposition' in Haitian, perhaps related in turn to the postrelative D.

On relative clause extraposition, v. Kayne (2000b: chap. 15). Chomsky's (2001b) suggestion in terms of qualification/afterthought is hard to reconcile with the permeability of 'extraposed' relative clauses to extraction seen in Norwegian (Taraldsen (1981)) and to some extent even in English - Chung and McCloskey (1983).

Another instance of English scrambling is indirectly reflected in:

(i ) ?Each other's friends have insulted John and Bill once again.

(ii) *Each other have/has insulted John and Bill once again.

which strongly recalls the Japanese contrast discussed by Miyagawa (1997:4-5). (In (i) each other's friends have insulted must have moved leftward past the previously preposed John and Bill.)

24 A wide range of phenomena are analyzed in similar fashion in Kayne (1998). Cf. also Simpson and $\mathrm{Wu}(2002 \mathrm{~b})$.

25 See Kayne (1979). 
sentences appear to be close English counterparts of the well-known Icelandic transitive expletive construction. Jonas and Bobaljik (1993: $75 \mathrm{n}$ ) in fact take (3) to be an instance of that construction, combined with heavy-NP shift.

Put another way, (3) should be thought of as having a derivation involving a prior stage of the form '... (there) a shell fired by our own troops hit the building.' Subsequently, the VP 'hit the building' moves leftward past the subject (but to a position lower than the (final) position of expletive there).

The fact that, in order to produce a grammatical output here, English, but not Icelandic, must have VP-movement apply can now be related to another difference between English and Icelandic concerning negation:

(4) John has seen noone.

(5) *John has noone seen.

In Icelandic the judgments are reversed, despite the fact that Icelandic is VO. My proposal in Kayne (1998) was that the negative noone moved leftward past the verb in both languages. Only in English is that negative phrase movement followed by VP-movement, arguably the same, or nearly the same, leftward VP-movement, as in (3). Leftward VP-movement thus allows us to tie together (3) and (4) in English vs. Icelandic in a natural way. ${ }^{26}$

The shifted (leftward-moved) subject in (3) is indefinite, suggesting that scrambling of indefinites is available. This conclusion is quite likely to be supported by properties of Eastern Armenian set forth by Tamrazian (1994), my interpretation of which is that in Eastern Armenian focalized phrases, wh-phrases, some adverbs and also indefinites obligatorily move to the specifier position of the auxiliary. (If a given sentence contains an overt auxiliary but no focus/wh/adv/indefinite, then it is the VP that moves to Spec, aux.)

A separate question is whether indefinites (and definites) ever remain

26 On the other hand, Icelandic does seem to allow word-for-word counterparts of:

( i ) I will read only this book.

which suggests, if Kayne (1998) is right about only, that Icelandic has VP-preposing here. 
in situ. Diesing's (1992) discussion of German does take indefinites to remain in situ. Eastern Armenian makes one wonder if that is correct (it might be possible to maintain her primary intuition by saying that indefinites must end up in a position lower than the position in which definites end up). ${ }^{27}$

\section{4. "OVX Languages}

There are 'OVX' languages (where $\mathrm{X}$ corresponds to other constituents within VP) like Bambara and Kpelle, as discussed by Koopman (1992: 557) and Travis (1989: 269). And as is often the case, a general characteristic of one language may be found to hold for 'part' of another. Thus Irish infinitivals (cf. McCloskey and Sells (1988: 148)) look a bit like 'OVX,' as does Gwari (cf. Hyman and Magaji (1970: 92)) in at least some sentences with auxiliaries.

But (v. Dryer (1991)) there seem to be no 'XVO' languages such that $\mathrm{O}$ is a single object and $\mathrm{X}$ everything else within VP. ${ }^{28}$ From the present perspective, OVX would appear to reflect leftward preposing of the object alone to a particular Spec. A rightward counterpart that would allow XVO is excluded in principle. (The theory must also prohibit languages that would allow movement of $\mathrm{XV}$ across a single $\mathrm{O}$ while disallowing it across more than just $\mathrm{O}$.)

Creissels (2000: 252) says that OVX always has AuxV. In particular, there are AuxOVX languages. (The question of possible OAuxVX languages (or subparts of languages) needs to be looked into.) If Creissels is right, there are however no OVAuxX or OVXAux. The exclusion of the latter type is very likely to fall under the discussion of section 3.2 above.

27 Nilsen (2003) takes indefinites (in Norwegian) to move to a focus position. His discussion, which is important for the general question of objects in VO languages, contains interesting proposals about what triggers movements.

The discussion in section 2.1 above shows that German objects cannot be taken to be in situ in a complement position to the left of $\mathrm{V}$, but they could perhaps in some cases be in situ within a remnant-moved VP — see Haegeman $(2000 ; 2001)$.

28 Chinese allows more than just one object to follow V-see Huang (1994) for a Larsonian V-raising approach. Huang also argues (p. 27) for the preposing in Chinese of a gerundial VP whose V has been previously raised, i.e. for (remnant) movement of VP. 
The absence of OVAuxX appears to contrast with the existence of some VAuxOA languages (with $\mathrm{A}=\mathrm{adverbial} /$ adjunct) in the Bantoid, Cross River, Central Nigerian and West Benue-Congo families, according to Williamson and Blench (2000: 31ff.). ${ }^{29}$ (Perhaps OVX reflects some relation between the privileged object and a higher Aux.)

\subsection{Subordinating Conjunctions}

According to Appleyard (1995: 183-199), Amharic necessarily has, for if John likes linguistics, the equivalent of 'John linguistics if likes,' with 'if' immediately preverbal and in turn preceded by all the other components of the clause. ${ }^{30}$ In Kayne (2000a), I suggested an analysis whereby Amharic, 'starting from' a structure that resembles the actually occurring English one, preposes all the (non-clitic) arguments leftward past if (and similarly with other conjunctions).

But there seem to be no mirror-image languages to Amharic in this respect, i.e. no language seems to have the equivalent of 'likes if linguistics John' (or 'likes if John linguistics'), with 'if' immediately postverbal and everything else following. Again, the leftward movement(s) used by Amharic have no rightward counterpart.

The apparent absence of 'reverse' Amharic with respect to subordinating conjunctions needs to be contrasted with the behavior of the whword corresponding to 'where' in Siswati, a SVO Bantu language (cf. Taljaard et al. (1991: 121)) in which 'where' looks like a postverbal clitic (recalling the (non-postverbal) clitic status of 'where' in some North Italian dialects studied by Poletto (2000: 74)). It may be that Siswati has remnant movement past 'where' (cf. Buell (2002)), with that remnant movement perhaps to be understood as a case of pied piping of the verb by the subject. It may further be the case that remnant movement carrying a verb past a subordinating conjunction is possible only if interpretable as pied piping by a DP, in which case reverse Amharic would (correctly) not be accessible.

29 I've used Aux where they use M (for Modal).

30 Basque has something similar, with '... if Aux' - for relevant discussion, see Haddican (2001).

There may also be a link to the syntax of the Amharic relative marker discussed in Gragg (1972). 


\subsection{Negation and Auxiliaries}

Basque is a VAux language that allows Aux ... V if Aux is accompanied by negation. ${ }^{31}$ A conjecture worth testing would be:

(6) No AuxV language has V... Aux licensed by negation.

\subsection{DP}

Cinque (1996: §4) has shown that Greenberg's (1966) Universal 20 can be explained from the perspective of antisymmetry. The fact seems to be that 'Dem Num Adj' order is cross-linguistically found both prenominally and postnominally, whereas 'Adj Num Dem' order is found only postnominally. In effect, a bit as with Carstens's point about serial verbs from section 3.1 above, the stability of 'Dem Num Adj' order relative to the position of the noun gives us a window into UG that allows us to see that that order can be achieved independently of N/NP movement, whereas the order 'Adj Num Dem' cannot be. (A symmetric view of syntax would lead to the incorrect expectation that the two orders should be equally available. $)^{32}$

\section{Some Modifications}

\subsection{Word Order in Adjuncts vs. in Complements}

Vilkuna (1998: 216) says that Estonian and Finnish have verb-final order more consistently in non-finite adjuncts than in non-finite complements. Why should the adjunct vs. complement distinction, which is an external property of these non-finite clauses, at all correlate with their internal word order?

I think that this kind of correlation between internal and external properties is much more widespread than usually recognized and that it suggests important modifications in our picture of syntax.

In this particular case, what comes to mind is the possibility that nonverb-final order in non-finite clauses in Estonian and Finnish is determined as follows: The arguments that end up following the non-finite

31 See Laka (1990), Cinque (1999: 189) and Haddican (2002).

32 Nilsen (2003) observes that this point of Cinque's generalizes to adverb-VP ordering, to PP-VP ordering (v. Cinque (2002)) and to verb cluster formation (v. Koopman and Szabolcsi (2000)). 
verb must be (long-distance) scrambled out of the non-finite clause entirely, to an position high up in the matrix. Subsequent to which, remnant movement of the matrix VP (which will include the non-finite clause) takes the matrix VP to a still higher position. ${ }^{33}$ The reason that non-verb-final order in non-finite clauses is less readily available in adjuncts now reduces to the fact that extraction out of adjuncts is less readily available than extraction out of complements.

A partially similar point may be valid for (at least some) Italian. Antonino Gulli (personal communication) has told me that he makes the following distinction:

( 7 ) Gianni non sa, quel libro, se leggerlo.

('G neg knows, that book, if to-read-it')

( 8 ) * Gianni non sa, quel libro, se deve leggerlo.

('G neg knows, that book, if he-must to-read-it') (7) is a type of sentence discussed by Rizzi (1997). The phrase quel libro is left-dislocated out of the infinitive clause past the complementizer se (Cinque's (1990) clitic left-dislocation (CLLD)). But the corresponding finite case in (8) is not good, even though the complementizer is the same. A possible approach would be to have (7) derived by first preposing the 'if'-clause, then CLLDing quel libro out of the 'if'-clause into the matrix, then remnant-moving the matrix IP (not containing the 'if'-clause) past quel libro. The idea being that CLLD out of a preposed 'if'-clause into the matrix would be less accessible if the 'if'-clause is finite than if it is non-finite (as is often the case for long-distance extraction, though (much) more will need to be said to reconcile this with the fact that Italian is often rather free in its extractions).

\subsection{Adpositions and Complementizers}

The proposal of the preceding section has the property that it solves the problems addressed by denying that what looks like a constituent is one. For example, in (7) quel libro is actually in the matrix and there-

33 Cf. the derivations given in Kayne (1998) for the matrix scope negation in English sentences like:

(i) John will force his daughter to marry noone.

Cf. also Bayer (1993). 
fore does not form a constituent with se leggerlo, contrary to appearances, as indicated in the following (simplified) derivation:

(9) Gianni non sa [se leggerlo quel libro] $\rightarrow$ preposing of 'if'clause

[se leggerlo quel libro] Gianni non sa $t_{\mathrm{i}} \rightarrow$ CLLD of quel libro into matrix

quel libro ${ }_{j}\left[\left[\text { se leggerlo } t_{j}\right]_{i}\right.$ Gianni non sa $\left.t_{i}\right] \rightarrow$ remnant movement of IP

[Gianni non sa $\left.t_{\mathrm{i}}\right]_{\mathrm{k}}$ [quel libro $\left.\left.\mathrm{j}\left[\text { se leggerlo } t_{\mathrm{j}}\right]_{\mathrm{i}} t_{\mathrm{k}}\right]\right]$

In the last line of (9), 'quel libro se leggerlo $\left(t_{\mathrm{j}}\right)$ ' is not a constituent.

This is similar to a proposal I have made concerning prepositions and complementizers. Consider the following Greenbergian universal, which is exceptionless, according to Hawkins (1990:225) and Dryer (1992: 102):

(10) If a language is complementizer-final, then the language is OV.

One might try to understand this in terms of some notion of 'uniformity of headedness,' but as I argued in section 2.3 above, I don't think that that would be at all promising. Instead, I take (10) to be akin to the phenomena of section 4.1. The internal order of CP (whether C precedes or follows IP) appears to correlate with an external property of $\mathrm{CP}$ (whether it can follow the matrix verb or not).

In effect, (10) says that if $C$ follows IP, then the normal order of the language must have IP-C preceding $\mathrm{V}$ and never '*V-IP-C.'34 Why, however, should the internal order within $\mathrm{CP}$ be in any way universally keyed to the order between that CP and the matrix V (an 'external' property of CP). As in the discussion of (9), I think that the answer lies in the realization that we have to give up the idea that $\mathrm{CP}$ is a constituent of the familiar type. ${ }^{35}$

The same holds for PP, I think, once we distinguish the 'functional' adpositions from the 'lexical' (nominal) ones. As a first approximation, I take the functional adpositions to correspond to English to, at, from, by, with, for, of. Now Dryer (1992: 83) notes that the following

34 Specifying 'normal order' is necessary since, as Bayer (2001:32) points out, postverbal C-final clauses are possible in Marathi, Telugu and Malayalam.

35 See Kayne (2000b: chaps. 14, 15) for the details. 
is largely (though not completely) true:

(11) If a language is postpositional, then it is OV.

Let me strengthen this to:

(12) If the functional adpositions of a language are postpositions, then that language is OV.

which I conjecture to be exceptionless.

A strong interpretation of (12) has it that there can be no language whose normal word order is:

(13) *V DP P

where DP is what we call the object of $\mathrm{P}$ and $\mathrm{P}$ is a functional adposition.

As in the case of complementizers, what we have here is a correlation between what looks like an internal property of PP (whether P follows DP or not) and an external property of PP (whether it precedes or follows the matrix V). Again, I think that we can achieve a satisfactory account of this correlation only if we give up the idea that PP is a constituent of the familiar type.

The proposal is, first, that (functional) $\mathrm{P}$ is not merged directly with its 'object,' but is rather merged outside VP. And second, that P is typically paired with a head $\mathrm{K}$ (for Kase) that is visible in some languages and is also merged outside VP (but below P). ${ }^{36}$ A (simplified) derivation for John was looking at us would be as in:

(14) ... looking us $\rightarrow$ merger of $\mathrm{K}$

$\ldots \mathrm{K}$ looking us $\rightarrow$ movement of DP to Spec, $\mathrm{K}^{37}$

$\ldots \mathrm{us}_{\mathrm{i}} \mathrm{K}$ looking $t_{\mathrm{i}} \rightarrow$ merger of $\mathrm{P}$

$\ldots$ at $\left[\mathrm{us}_{\mathrm{i}} \mathrm{K}\right.$ looking $\left.t_{\mathrm{i}}\right] \rightarrow$ movement of VP to Spec,P

$\ldots$ [looking $\left.t_{\mathrm{i}}\right]_{\mathrm{j}}$ at $\left[\mathrm{us}_{\mathrm{i}} \mathrm{K} t_{\mathrm{j}}\right]$

This derivation produces the correct word order for an English-like language, without having 'at us' be a constituent.

\section{3. (Remnant) VP-Movement}

The derivation in (14) involves remnant VP-movement in the last

36 For details, see Kayne (to appear-b). Left open is the question how to get Case morphology on more than one element of DP in languages like Russian - for relevant discussion, see Kayne (to appear - a).

37 Cf. in part McCloskey (1984). 
step. Although the particular use I am putting it to here is perhaps unfamiliar, VP-movement per se is a long-standing part of our understanding of syntax. In English, we have sentences like:

(15) $\ldots$ and do it he will.

These are well-known. Less well-known about English is that it allows remnant movement in this construction. ${ }^{38}$ As background, note:

(16) I predicted that John would marry Susan, and marry Susan $/$ her $/ *$ Ann he will.

The argument(s) in the preposed VP must not be 'new information.' With this in mind, I find the following acceptable (with a 'coreferential' interpretation):

(17) I predicted that John would marry Susan, and marry he will the woman he loves.

Stranding a non-heavy object is not possible:

(18) $* \ldots$ and marry he will Susan/her.

Thus, (17) is an instance of remnant VP-movement. The 'heavy' $\mathrm{NP} / \mathrm{DP}$ the woman he loves has been moved out of the VP prior to the VP being fronted. (Recall from section 3.3 that 'heavy'-NP shift is itself a fronting (leftward movement) operation.) The derivation of (17) (simplified) will look like:

(19) marry the woman he loves $\rightarrow$ heavy-NP shift the woman he loves $\left[\right.$ marry $\left.t_{i}\right] \rightarrow \operatorname{merger}(\mathrm{s})$ he will the woman he loves [marry $t_{\mathrm{i}}$ ] $\rightarrow$ VP-preposing [marry $\left.t_{\mathrm{i}}\right]_{\mathrm{j}}$ he will the woman he loves $t_{\mathrm{j}}$

That 'heavy'-NP shift is involved in the derivation of (17) is supported by the fact that (17) is subject to two well-known restrictions holding of heavy-NP shift in general:

$(20)^{*}$ ? I predicted that John would look at Susan and look at he will the woman he loves.

(21) *I predicted that John would send Susan some flowers and send some (flowers) he will the woman he loves.

In addition to the preposition stranding restriction seen in (20), we see

38 Less robustly than in Dutch or German (see den Besten and Webelhuth's (1990) important paper) and less robustly than in mainland Scandinavian, for reasons likely having to do with the absence of V-2 in English. 
in (21) that a prepositionless indirect object is not subject to heavy-NP shift.

The problem with (21) is not that the preposed VP contains a visible argument, since we do have: ${ }^{39}$

(22) I predicted that John would send Susan those flowers, and send her he will the flowers he loves.

(23) I predicted that John would speak French to Susan, and speak French he will to the woman he loves.

In my English, the preposition restriction in (20) is somewhat weak, but gets much stronger in the presence of a direct object:

(24) *I predicted that John would introduce you to Susan, and introduce you to he will the woman he loves.

As expected, this distinction matches my judgments on 'simple' heavyNP shift sentences:

$(25)^{*}$ ? John will look at tomorrow the article you just sent him.

(26) *John will introduce you to tomorrow the woman he loves.

Remnant VP-movement is thus found in all of (14), (17), (22) and (23), though the landing sites for the moved VP are not uniform.

\subsection{Postpositions}

In Kayne (1994: 49) I took the difference between postpositional and

39 When what is stranded by VP-preposing is a PP, heaviness is much less necessary:

(i ) ?... and speak French he will to her.

On PP being able to be moved leftward out of VP more readily than DP, see Kayne (1994: 75).

These cases where the preposed VP contains more than just V pose a problem for Chomsky's (2001a) approach to (Scandinavian) object shift, as do Scandinavian examples of the same sort.

Other examples from English:

(ii ) $\ldots$ and put on the table he did the book he had written.

(iii) $\ldots$ and show me he did the book he had written. vs.

(iv) $\ldots$ and give it I did *(to) the colleague I had mentioned.

In Norwegian, this is possible even with direct object pronouns, as Taraldsen has noted:

(v ) Lagt på bordet har jeg dem ikke. ('put on table-the have I them not') As expected if this is really object shift (of the mainland Scandinavian sort), Taraldsen gets a sharp contrast with lexical DPs:

(vi) *Lagt på bordet har jeg bokene ikke. 
prepositional phrases to be that postpositional phrases involved movement of the complement of P to the Spec of P and I assumed absence of movement with prepositions. The derivation in (14), however, does attribute movement to the object of a preposition, though the movement is to Spec, $\mathrm{K}$, not to Spec,P. (This movement to Spec, $\mathrm{K}$ in the case of prepositional objects is intended to be strongly similar to the more familiar movements to nominative and accusative-licensing positions. ${ }^{40}$ ) What does move to Spec, $\mathrm{P}$ in the case of prepositions is VP.

The question is now how to best analyze postpositions of the sort found in Japanese. Let me suggest the following unification:

(27) Spec,P is never filled by DP.

At first glance, this may seem surprising, but we need to take into account languages (e.g. Turkish, Hindi, Hungarian) that have overt Case morphology in addition to postpositions; when the two cooccur we typically, if not always, find the order 'DP-K-P' rather than 'DP-P$\mathrm{K}$.' Let us further assume, in the spirit of Vergnaud's original ideas about Case, that all languages with postpositions have a $\mathrm{K}$ (and that the order is 'DP-K-P'). In which case, DP will obviously not be the sole occupant of Spec,P and (27) holds.

A further unifying hypothesis would be:

(28) (Functional) $\mathrm{P}$ and associated $\mathrm{K}$ are always merged outside VP.

Putting (28) together with the need to produce 'DP-K-P' sequences leads to the following proposal for postpositions (adapting ideas of Pearson's (1997)). ${ }^{41}$ We start out as in the derivation given in (14) for prepositions:

(29) ... looking us $\rightarrow$ merger of $\mathrm{K}$

$\ldots \mathrm{K}$ looking us $\rightarrow$ movement of DP to Spec, $\mathrm{K}$

$\ldots \mathrm{us}_{\mathrm{i}} \mathrm{K}$ looking $t_{\mathrm{i}}$

But instead of introducing $\mathrm{P}$ immediately, we introduce an unpronounced double of $\mathrm{P}$ (which I will call $\mathrm{P}^{\prime}$ ) to whose Spec VP moves (just as VP moves to Spec,P in (14), with prepositions):

40 See Kayne (to appear - c).

41 I am setting aside the question of sentences with multiple Ps. 
(30)

$\ldots \mathrm{us}_{\mathrm{i}} \mathrm{K}$ looking $t_{\mathrm{i}} \rightarrow$ merger of $\mathrm{P}^{\prime}$

... $\mathrm{P}^{\prime} \mathrm{us}_{\mathrm{i}} \mathrm{K}$ looking $t_{\mathrm{i}} \rightarrow$ movement of VP to Spec, $\mathrm{P}^{\prime}$

... [looking $\left.t_{\mathrm{i}}\right]_{\mathrm{j}} \mathrm{P}^{\prime} \mathrm{us}_{\mathrm{i}} \mathrm{K} t_{\mathrm{j}}$

At this point, $\mathrm{P}$ is merged, and KP moves to its Spec:

(31) $\quad \ldots$ [looking $\left.t_{\mathrm{i}}\right]_{\mathrm{j}} \mathrm{P}^{\prime}$ us $\mathrm{K} t_{\mathrm{j}} \rightarrow$ merger of $\mathrm{P}$

$\ldots$ at [looking $\left.t_{\mathrm{i}}\right]_{\mathrm{j}} \mathrm{P}^{\prime} \mathrm{us}_{\mathrm{i}} \mathrm{K} t_{\mathrm{j}} \rightarrow$ movement of KP to Spec,P

$\ldots\left[\mathrm{us}_{\mathrm{i}} \mathrm{K} t_{\mathrm{j}}\right]_{\mathrm{k}}$ at [looking $\left.t_{\mathrm{i}}\right]_{\mathrm{j}} \mathrm{P}^{\prime} t_{\mathrm{k}}$

This yields the correct word order for preverbal postpositions of the Japanese sort. The DP (us) and P (at) do not form a constituent, just as they did not in the derivation of postverbal prepositions in (14).

Note that we now have (the outline of) an account of $(12) /(13)$. Given (27), (13) is ruled out immediately. To express the full content of (12), however, we also need to rule out:

(32) *V DP K P

where DP is the object of (functional) $\mathrm{P}$.

Assume that we have reached the last line of (29), yielding (apart from traces) ' $\mathrm{DP} \mathrm{K} \mathrm{V}$ ' and that we then introduce $\mathrm{P}$, with the result ' $\mathrm{P}$ DP K V.' Since 'DP K' is not a constituent there, it cannot be moved to Spec, $\mathrm{P}$. We could move 'DP K' by moving KP (containing V), which would yield 'DP K V P' - arguably never attested, because of a general prohibition against moving the complement of $\mathrm{X}$ to the Spec of $\mathrm{X}$ - and which is in any case not heading toward (32). Alternatively, having reached 'P DP K V', we could move VP to Spec, $\mathrm{P}$, yielding ' $\mathrm{V}$ P DP K' (as in (14)). But that still does not provide a way of reaching (32) (unless we subsequently allowed KP to move and 'tuck in' to a second Spec of P (a la Richards (1997)), which I have taken not to be an available option). ${ }^{42}$ I conclude that (32) is not reachable via a derivation using $\mathrm{P}$ and $\mathrm{K}$ as heads external to $\mathrm{VP}$.

We also need to make sure that the unpronounced $\mathrm{P}^{\prime}$ of $(30) /(31)$ does not make (the equivalent of) (32) accessible. Let us return to 'DP K V' and let us introduce $\mathrm{P}^{\prime}$, keeping $\mathrm{P}$ in abeyance. This yields ' $\mathrm{P}$ ' DP K V.' Again, 'DP $\mathrm{K}$ ' is not a constituent and cannot move alone. Let us move VP to Spec, $\mathrm{P}^{\prime}$, as in (30), yielding ' $\mathrm{V} \mathrm{P}^{\prime}$ DP K.' Introducing $\mathrm{P}$ leads to ' $\mathrm{P} V \mathrm{P}^{\prime} \mathrm{DP} \mathrm{K}^{\prime}$ ' and moving $\mathrm{KP}$ to $\mathrm{Spec}, \mathrm{P}$ yields

42 Remnant movement may provide a new handle on many of the cases for which 'tucking in' seemed necessary. 
'DP K P V P', ' as in the last line of (31). Since there are no multiple Specs, further movement is impossible unless we introduce another head $\mathrm{X}$ - ' $\mathrm{X}$ DP K P V P' - to which we can move $\mathrm{P}^{\prime} \mathrm{P}$, yielding ' $\mathrm{V}$ $\mathrm{P}^{\prime} \mathrm{X}$ DP K P.' If this $\mathrm{X}$ is silent, we get what looks like (32). Therefore either there is no such silent $X$ available at all in UG or else any such silent $\mathrm{X}$ (coming in directly above $\mathrm{P}$ ) will have specific content that will make ' $\mathrm{V} \mathrm{P}^{\prime}$ X DP K P' a marked construction (e.g. focus/ topic).

From the perspective of feature-driven movement, $\mathrm{P}^{\prime}$ in (30) and prepositional $\mathrm{P}$ in (14) could be thought of as having a $\mathrm{V}$-feature that attracts VP, and postpositional $\mathrm{P}$ of the Japanese sort in (31) as having a K-feature that attracts KP. ${ }^{43}$

\subsection{Prepositional Complementizers}

In Kayne (2000b: chaps. 14, 15), I suggested an approach to initial complementizers parallel to that discussed above for prepositions. This parallelism is particularly natural in the case of prepositional complementizers like French $d e$, Italian $d i$ and English to. (I take English to to be a subtype of complementizer. Differences between it and $d e / d i$ and between it and English that can be attributed to independent factors.)

That English infinitival to is prepositional is consistent with, if not actually supported by, the fact that it (sometimes) allows stranding under movement, as English prepositions often do:

(33) They predicted that John would have to resign, and resign he'll have to.

If infinitival to is strongly parallel to other English prepositions, then it should enter derivations like the following (of ... try to leave), matching the derivation of ... looking at us given in (14):

$\ldots$ try leave $\rightarrow$ merger of $\mathrm{K}$

$\ldots \mathrm{K}$ try leave $\rightarrow$ movement of InfinP to Spec, $\mathrm{K}$

$\ldots$ leave $_{\mathrm{i}} \mathrm{K}$ try $t_{\mathrm{i}} \rightarrow$ merger of $\mathrm{P} / \mathrm{C}$

$\ldots$ to $\left[\right.$ leave $\mathrm{K}$ try $\left.t_{\mathrm{i}}\right] \rightarrow$ movement of VP to Spec, $\mathrm{P} / \mathrm{C}$

$\ldots\left[\operatorname{try} t_{\mathrm{i}}\right]_{\mathrm{j}}$ to $\left[\right.$ leave $\left.\mathrm{K} t_{\mathrm{j}}\right]$

43 Beyond the scope of this paper are postpositions of the Dutch/German sort recently discussed by van Riemsdijk and Huybregts (to appear). 
As before, to leave in the last line of (34) is not a constituent (although 'to leave $\mathrm{K} t_{\mathrm{j}}$ ' is).

As in the rest of English (apart from pronouns), $\mathrm{K}$ is not pronounced. In German, whose $z u$ should almost certainly be treated like English to, $\mathrm{K}$ might conceivably correspond to the infinitival $-(e) n$, but it is more likely that $-(e) n$ is a distinct functional head, and $\mathrm{K}$ is not pronounced in German, either (just as the dative Case that normally goes with $z u$ is sometimes not pronounced on nouns).

It should be noted that the stranding seen in (33) with infinitival to is not possible with the standard English for that is found with some infinitivals. There is a sharp contrast between:

(35) They predicted that he'd want to leave early, and leave early he'll want to.

(36) *They predicted that he'd want for them to leave early, and them to leave early he'll want for.

This for is usually thought of as a complementizer. It may, from the present perspective, enter into the following type of derivation:

(37) $\ldots$ want them leave $\rightarrow$ merger of $\mathrm{K}_{\text {for }}$

$\ldots \mathrm{K}_{\text {for }}$ want them leave $\rightarrow$ movement of them to $\mathrm{Spec}, \mathrm{K}_{\text {for }}$

$\ldots$ them $\mathrm{K}_{\mathrm{i}} \mathrm{K}_{\text {for }}$ want $t_{\mathrm{i}}$ leave $\rightarrow$ merger of for

$\ldots$ for them $\mathrm{K}_{\text {for }}$ want $t_{\mathrm{i}}$ leave $\rightarrow$ movement of matrix VP to Spec, for

$\ldots$ [want $t_{\mathrm{i}}$ leave $]_{\mathrm{j}}$ for them $\mathrm{K}_{\mathrm{i}} t_{\mathrm{j}} \rightarrow$ merger of $\mathrm{K}_{\mathrm{to}}$

$\ldots \mathrm{K}_{\mathrm{to}}\left[\text { [want } t_{\mathrm{i}} \text { leave }\right]_{\mathrm{j}}$ for them $\mathrm{K}_{\text {for }} t_{\mathrm{j}} \rightarrow$ movement of embedded VP leave to Spec, $\mathrm{K}_{\mathrm{to}}$

$\ldots$ leave $_{\mathrm{k}} \mathrm{K}_{\text {to }}\left[\text { want } t_{\mathrm{i}} t_{\mathrm{k}}\right]_{\mathrm{j}}$ for them $\mathrm{K}_{\mathrm{i}} \mathrm{K}_{\text {for }} t_{\mathrm{j}} \rightarrow$ merger of $t o$

... to leave $\mathrm{k}_{\mathrm{k}} \mathrm{K}_{\mathrm{to}}$ [want $\left.t_{\mathrm{i}} t_{\mathrm{k}}\right]_{\mathrm{j}}$ for them $\mathrm{K}_{\mathrm{i}} \mathrm{K}_{\text {for }} t_{\mathrm{j}} \rightarrow$ movement of forP to Spec, to

$\ldots$ : [ wwant $\left.t_{\mathrm{i}} t_{\mathrm{k}}\right]_{\mathrm{j}}$ for them $\left.\mathrm{K}_{\mathrm{i}} \mathrm{K}_{\text {for }} t_{\mathrm{j}}\right]_{1}$ to leave $_{\mathrm{k}} \mathrm{K}_{\mathrm{to}} t_{\mathrm{l}}$

In the last line of this derivation, we see that them to leave is not a constituent. The ungrammaticality of (36) follows from that.

The movement of for $\mathrm{P}$ to Spec, to in the next-to-last line should almost certainly be thought of as a case of pied-piping, with for $\mathrm{P}$ being pied-piped by the VP in its Spec. The movement of the embedded VP leave to $\mathrm{Spec}, \mathrm{K}_{\mathrm{to}}$ in the sixth line involves movement from within a left branch - it may be that left-branch violations of the familiar sort can be reduced to 'complex NP' violations (and/or Specificity Condition 
violations ${ }^{44}$ ), if sentential subjects/topics ${ }^{45}$ are generally DPs (which want leave in the sixth line is not), as they visibly are in some languages (e.g. Greek).

We need to ask now why English is so unusual (at least relative to other Germanic languages and to Romance languages) in having an infinitival for ... to ... construction with a lexical (accusative) subject following for ${ }^{46}$ In part this property of English is likely to be closely correlated with the fact that English has ECM-constructions of the believe-type, ${ }^{47}$ in that the movement of them (to $\mathrm{Spec}, \mathrm{K}_{\mathrm{for}}$ ) in the second line of (37) is of the ECM-type (movement of the subject, out of an infinitival). No Romance language has believe-type ECM to the degree that English does. (For a fine-grained study of the differences, see Pollock (1985).) This is not sufficient to account for the contrast with the rest of Germanic, though, since Icelandic has robust ECM of the believe-type, but nothing comparable to for ... to. For Icelandic, one can point to its requiring morphological oblique Case with its prepositions as probably being relevant (though that would not extend to mainland Scandinavian, which seems to have some believe-type ECM). The exact parameters at issue remain to be delineated. ${ }^{48}$

The fact that for requires an infinitival, as opposed to a finite IP, may follow from the fact that the subject of a finite IP will already have been Case-marked and therefore 'frozen' with respect to further movement of the sort related to Case (as is movement to $\mathrm{K}_{\text {for }}$ ): ${ }^{49}$

(38) *John would like for her leaves.

The fact that for is not compatible with gerunds:

44 See Fiengo and Higginbotham (1981).

45 Thinking of Koster (1978).

46 I am leaving aside here the non-standard for ... to constructions studied by Henry (1995).

47 And of course of the want-type without for, as in:

(i ) John wants them to leave.

These are also cross-linguistically unusual (at least relative to Germanic and Romance), but they may themselves contain an unpronounced for (see Kayne (1981a)), contrary to the believe-type.

48 If recent theoretical developments are on the right track (cf. Chomsky (1995)), then the government-based proposal of Kayne (1981b) concerning ECM would be expected not to be entirely correct.

49 Cf. Chomsky (2000). 
(39) *John would be happy for there being another party. could be accounted for in the same way, if a lexical subject in a gerund must get Case within the gerund. ${ }^{50}$

\subsection{Non-Prepositional Complementizers}

The stranding seen in (33) has no counterpart with non-prepositional complementizers like English that or if:

(40) *They predicted that he'd be happy that he could help us, and he can help us he'll be happy that.

(41) *They predicted that he wouldn't be sure if he could help us, and he can/could help us he won't be sure if.

These contrast sharply with:

(42) (?)They predicted that he'd be happy to help us, and help us he'll be happy to.

Although the sharp impossibility of $(40) /(41)$ resembles that of (36), the proposal for (36) made in effect in (37) (based on non-constituency) probably does not carry over to $(40) /(41)$, given that for and that/if differ substantially. In particular, unlike for, that and if have counterparts in Romance languages and in the other Germanic languages. A natural way to interpret this fact is to say that neither that nor if involves an ECM-like extraction of the embedded subject in the way that for does in (37). In other words, as suggested by (38), too, the subject of a finite sentence is Case-licensed independently of that/if, a conclusion reinforced by consideration of finite relative clauses, which typically allow lexical subjects, despite frequently (depending on the language) not having any (overt) complementizer.

Relative clause complementizers of the English sort, which precede their associated IP, like English that, were given in Kayne (2000b: chap. 15) a derivation similar to that given above in (14) for prepositions and in (34) for prepositional complementizers, but without $\mathrm{K}$. That is merged outside VP. If we extend this to non-relative sentential that, and maximize uniformity by associating a $\mathrm{K}$ with that, too, we would have derivations like:

50 For relevant discussion, see Reuland (1983) and Raposo (1987). 
... think they're smart $\rightarrow$ merger of $\mathrm{K}_{\text {fin }}$

$\ldots \mathrm{K}_{\mathrm{fin}}$ think they're smart $\rightarrow$ movement of IP to $\mathrm{Spec}, \mathrm{K}_{\mathrm{fin}}$

... [they're smart $]_{\mathrm{i}} \mathrm{K}_{\text {fin }}$ think $t_{\mathrm{i}} \rightarrow$ merger of that

... that [they're smart] $\mathrm{K}_{\mathrm{fin}}$ think $t_{\mathrm{i}} \rightarrow$ movement of VP to Spec, that

$\ldots$ [think $\left.t_{\mathrm{i}}\right]_{\mathrm{j}}$ that [they're smart $]_{\mathrm{i}} \mathrm{K}_{\text {fin }} t_{\mathrm{j}}$

The last line of (43) is parallel to the last line of (34).

This, however, leaves open the contrast (with respect to stranding of to vs. that) between $(33) /(35) /(42)$ on the one hand and (40) on the other. The solution, I think, is to go back to Rosenbaum's (1967) idea that that-clauses are introduced by it, and to say that contrary to the impression given by (43), the finite IP they're smart is not, and could not by itself be, an argument of the matrix verb think. More generally put: 51

(44) A finite IP cannot be the argument of a higher predicate. Let me take this to lead to:

(45) For an IP to function as the argument of a higher predicate, it must be nominalized.

The idea is that this can happen in one of two ways, broadly speaking - either through nominalizing morphology or through merger with a noun. (These are very likely just two variants of what is essentially one strategy, insofar as nominalizing morphemes are 'bound' variants of 'free' nouns.)

In English, this nominalizing morphology can be of the derived nominal (-ion) type, or of the gerundial (-ing) type or of the (null) infinitival type. It is probably the case, as a first approximation, that the -ion-type is always further embedded under a $\mathrm{D}$, that the -ing-type

51 Cf. Kayne (1982).

IP here should perhaps be taken to include projections like FocusP and TopicP that are part of Rizzi's (1997) Comp area. Alternatively, $\mathrm{Foc}^{0}$ and $\mathrm{Top}^{0}$ might be merged above VP, parallel to complementizers. $\mathrm{K}_{\text {fin }}$ in (43) might be assimilated to one of these heads or to Rizzi's Fin ${ }^{0}$; alternatively, see Fabb (1984).

On complementizers that look medial, like to in:

( i ) John doesn't know where to go.

see Kayne (2000b: chap. 14) and/or Buell (2002). Possibly, the analysis of (i) could be extended to cover Barbiers's (2000b) LAS.

The status of quotative complementizers needs to be looked into further - for interesting discussion, see Koopman and Sportiche (1989). 
usually is, and that infinitives often are not.

In the absence of nominalizing morphology, i.e. when the verb is finite, the IP must be embedded under a non-affixal noun, which can be fact, in which case further embedding under (definite) $\mathrm{D}$ is required:

(46) John mentioned *(the) $/ *$ a fact that Mary was away.

This might hold in general, i.e. even when the noun that the finite IP is embedded under is not pronounced. In other words, in:

(47) John thinks that Mary is away.

there might be both an unpronounced $\mathrm{N}$ (imposed by (45)) and an unpronounced D. Yet (46) and (47) diverge when it comes to adjectives:

(48) John is aware *(of) the fact that they're away.

(49) John is aware (*of) that they're away.

Let me tentatively take this to suggest than an unpronounced $\mathrm{N}$ need not be further embedded under $\mathrm{D}$, that it is not in (49), ${ }^{52}$ and that the Case requirement that imposes of on (48) is keyed to D rather than to N. ${ }^{33}$

The derivation given in (43) needs to be revised to take into account the presence of this $\mathrm{N}$ (and in some cases $\mathrm{D}$, which $\mathrm{I}$ will set aside here). The new derivation containing unpronounced $\mathrm{N}$ will begin:

(50) $\ldots$ think $\mathrm{N}$ they're smart $\rightarrow$ merger of $\mathrm{K}_{\text {fin }}$

$\ldots \mathrm{K}_{\text {fin }}$ think $\mathrm{N}$ they're smart

The next step is movement to $S p e c, K_{\text {fin }}$. But now a question arises that did not arise earlier (in (43)), namely whether to move IP or NP. Let us entertain the hypothesis that what moves at this point is NP:

52 Even though the embedding in (49) is factive - for relevant discussion, see Barbiers (2000a).

If the finite IP is an argument of realization or realize in:

(i) the realization that he's exhausted then it, too, must be embedded under N; for relevant discussion, see Stowell (1981) and Pesetsky (1995).

53 Island effects may also be sensitive to whether or not D is present. 
(51) $\ldots \mathrm{K}_{\mathrm{fin}}$ think $\mathrm{N}$ they're smart $\rightarrow$ movement of NP to Spec, $\mathrm{K}_{\text {fin }}$

$\ldots$ [N they're smart $]_{\mathrm{i}} \mathrm{K}_{\mathrm{fin}}$ think $t_{\mathrm{i}} \rightarrow$ merger of that

$\ldots$ that $[\mathrm{N} \text { they're smart }]_{\mathrm{i}} \mathrm{K}_{\text {fin }}$ think $t_{\mathrm{i}} \rightarrow$ movement of $\mathrm{VP}$ to Spec, that

... [think $\left.t_{\mathrm{i}}\right]_{\mathrm{j}}$ that $[\mathrm{N} \text { they're smart }]_{\mathrm{i}} \mathrm{K}_{\mathrm{fin}} t_{\mathrm{j}}$

This derivation may help in understanding why complementizer that looks like demonstrative that (especially if Sportiche (2002) is on the right track), though there is no immediate generalization to the complementizer that of English relative clauses. On the other hand, perhaps there should not be one, given languages like German, which have a sentential complementizer (dass) that looks like a demonstrative/definite article (das) yet does not occur in relatives in the way that that does in English. ${ }^{54}$

Consider now the result of replacing think in (50)/(51) by a verbparticle combination. The relevant sentence is:

(52) John pointed out that they're smart.

Assume that the particle out is within the matrix VP and that it (therefore) enters the derivation prior to $\mathrm{K}_{\text {fin }}$ :

(53) $\ldots$ point $\left[\mathrm{N}\right.$ they're smart] out $\rightarrow$ merger of $\mathrm{K}_{\text {fin }}$

$\ldots \mathrm{K}_{\text {fin }}$ point [ $\mathrm{N}$ they're smart] out $\rightarrow$ movement of $\mathrm{NP}$ to Spec, $\mathrm{K}_{\mathrm{fin}}$

$\ldots$ [N they're smart $]_{\mathrm{i}} \mathrm{K}_{\text {fin }}$ point $t_{\mathrm{i}}$ out $\rightarrow$ merger of that

$\ldots$ that $[\mathrm{N} \text { they're smart }]_{\mathrm{i}} \mathrm{K}_{\text {fin }}$ point $t_{\mathrm{i}}$ out $\rightarrow$ movement of $\mathrm{VP}$ to Spec, that

$\ldots$ [point $t_{\mathrm{i}}$ out $]_{\mathrm{j}}$ that $[\mathrm{N} \text { they're smart }]_{\mathrm{i}} \mathrm{K}_{\mathrm{fin}} t_{\mathrm{j}}$

In the last step, out is carried along by VP-movement, yielding (52).

54 The English that-relative does not occur in any Germanic OV language, as far as I know (setting aside adverbials - Smits (1989: 67)). Similarly for the English 'zero relative' (as in the man we saw). Nor does the English that-relative occur in any Scandinavian, that I know of. (Scandinavian relatives are introduced by $\mathrm{som} / \mathrm{sem}$, which is close to English as.) Mainland Scandinavian has zero relatives but Icelandic does not, it seems, perhaps for reasons related to the difference in verb movement in embeddings. All of this requires further work.

Thráinsson (1994: 186) says that dropping the sentential complementizer adh in Icelandic is possible only if the subject is pronominal. Cf. the judgments on certain cases in English given in Kayne (1994: 156). 
(This is independent of the decision to have NP rather than IP move to Spec, $\left.\mathbf{K}_{\text {fin }}.\right)$

Since the movement of VP carries along the particle out, there is in fact no way, given our general approach plus the assumption that out is within VP, to derive:

(54) *John pointed that they're smart out.

(More precisely put, there is no way to derive (54) without introducing the sort of scrambling operation that Kayne (1998) argued to be unavailable with English particles. ${ }^{55}$ ) In other words, we have a possible grammatical account of (54) (independent of any processing considerations).

That $\mathrm{K}_{\mathrm{fin}}$, and hence complementizer that, is merged above VP may be relevant to a striking discrepancy that emerges between complementizer that and demonstrative that, or more exactly between their counterparts in languages with rich Case morphology. In German, Icelandic and Russian, for example, demonstratives show Case morphology, but complementizers never do. A possible account is that the $\mathrm{K}$ heads that correspond to nominative, accusative, dative, etc. are all merged within VP (and above demonstratives) but (therefore) below complementizers. (Any (functional) $\mathrm{P}$ paired with a VP-internal $\mathrm{K}$ would likewise be merged below complementizers (but above demonstratives/determiners).) This would show up in the fact that while $\mathrm{P}$ can usually be followed by $\mathrm{D}$, for $\mathrm{P}$ to be immediately followed by $\mathrm{C}$ is rare. ${ }^{56}$ )

55 Cf. den Besten and Webelhuth (1990) on Dutch and German particles, and Kayne (2000b: chap. 15) on the parallel fact with relatives:

(i ) *John pointed the student who was causing trouble out.

(Leftward) scrambling of the sort alluded to in the text is available (with to all his friends) in:

(ii) John pointed out that they're smart to all his friends.

(iii) John pointed out the student who was causing trouble to all his friends.

Almost certainly related to (i) and (54) is Kornfilt's (1995) observation that the Turkish postverbal $\mathrm{C} / k i$-initial ' $\mathrm{CP}$ ' often used in quotations (but not only) must be clause-final.

Also like (i) is the fact, brought to my attention by Francisco Ordóñez, that Spanish VSO sentences can have a relative clause within the subject if the object is definite, but not if the object is indefinite with no article.

56 On the (frequent) impossibility of $\mathrm{P}$ followed by C, see Kayne (2000b: chap. 14). 
Returning now to (40) (and by extension (41)), we are now in a position to attribute to (40) the presence of an unpronounced non-affixal $\mathrm{N}$ just as in (49), in which case we can correlate the deviance of (A-bartype) IP-preposing in (40) with the presence of that $\mathrm{N}$ (thinking perhaps of the complex-NP constraint). If, furthermore, we agree that infinitives, by virtue of being an instance of nominalizing morphology, do not systematically require embedding under non-affixal $\mathrm{N}$, and more specifically that (42) does not contain one, we might then be able to account for the relative well-formedness of (42), since (42) will not run afoul of any complex-NP-like constraint (assuming the nominalizing morphology itself not to act like the non-affixal $\mathrm{N}$ of (40)). ${ }^{57}$

\subsection{Final Complementizers}

A number of languages have complementizers that follow the associated IP. On the other hand, Dryer (1996: 1053) seems to indicate that such complementizers are not common, i.e. are less common than one might have expected starting from a notion of 'uniform head-finality' (see section 2.3 above). Doing justice to the complexity and range of questions that arise concerning final complementizers would go beyond the scope of this paper; let me, however, try to provide a partial analysis.

Consider the case of an IP associated with a final complementizer, where that IP functions as the argument of some higher predicate. Then by (45), that IP must be nominalized, i.e. must occur with nominalizing morphology or be embedded under a free-standing $\mathrm{N}$, in a way that would be similar to English the fact that he's smart, ${ }^{58}$ abstracting

57 This kind of account would allow (finite) IP to be a phase - cf. in part Legate (to appear).

The discussion in this paragraph does not address the question why the stranding of to seems to have no counterpart in other Germanic languages and in Romance languages. (There is probably some link to VP-deletion.)

Nor does it address the contrast between (40) and well-formed extractions from within finite IP (which might begin prior to merger of $\mathrm{K}_{\mathrm{fin}}$ ):

(i ) How do you think that he'll answer the question?

58 It may be that $(44) /(45)$ should be generalized to cover relative clauses. Finite relatives would then meet the nominalization requirement by virtue of N/NP raising. This would imply an unpronounced 'head' $\mathrm{N}$ in finite free relatives, and might account for the fact that certain free relatives such as French: 
away from word order and from the presence/absence of the determiner.

Now recall from (10) that final complementizers normally go with $\mathrm{OV}$ and not with VO. This leads to the following conjecture:

(55) If an IP is associated with a final $\mathrm{C}$, and if that IP is embedded under $\mathrm{N}$, the order will universally be IP-C-N (and never *N-IP-C).

A parallel conjecture for the partially similar case of relative clauses would be:

(56) A relative clause with a final C must precede its 'head' N/NP.

(Both of these conjectures might need to be relativized to 'normal order (for the language in question),' abstracting away from special movement effects.)

The two related conjectures that follow also seem plausible:

(57) If an IP is associated with an initial $\mathrm{C}$, and if that IP is embedded under $\mathrm{N}$, the order will universally be $\mathrm{N}$-C-IP (and never ${ }^{*} \mathrm{C}$-IP-N).

(58) A relative clause with an initial $\mathrm{C}$ must follow its 'head' N/NP. ${ }^{59}$

To the extent that this set of conjectures is (largely) correct, it emphasizes the (partial) similarity between structures like the fact that $\ldots$ and relative clause structures. If that similarity is significant, then an observation by Keenan (1985:160) concerning relative clauses becomes relevant to the fact that ... and to IP arguments more generally. Keenan noted that cross-linguistically the verbs of prenominal relatives are with few exceptions non-finite/participial. Similarity with the fact that ... would then lead us to expect:

(59) When the embedded IP precedes (the equivalent of) fact, that IP will with few exceptions be non-finite/participial.

Consider now the case of a finite IP serving as the argument of a verb or adjective in a language that has only final complementizers. By (45), that finite IP must be embedded under N. By (55), the order

(i ) Vous avez de quoi manger. ('you have (of) what to-eat') have no finite counterparts.

Finite embedded interrogatives will also need an N.

59 Cf. Hawkins (1990: 242). 
must be 'IP-C-N.' By (59), the IP must therefore with few exceptions be non-finite/participial. Contradiction (in most cases). We therefore conclude that an IP accompanied by a final complementizer will usually be non-finite/participial. ${ }^{60}$

The English complementizer that has the property that it occurs only with finite IP. We therefore conclude further that (with few exceptions) there can be no 'final' counterpart of that, and that in languages that have only final complementizers there is likely to be no counterpart of English that at all - which is what Fukui (1986) claimed to be true for Japanese. ${ }^{61}$

\section{Conclusion}

Antisymmetry impinges on the analysis of Japanese in many ways, some of which I have touched on here. I have in addition argued that the solidity of the antisymmetry hypothesis is enhanced by a wide range of cross-linguistic gaps, i.e. imaginable language types that appear never to occur. I have argued further that adpositions are paired with a K-head and that DP-movement to Spec,K and VP-movement to Spec, $\mathrm{P} / \mathrm{P}^{\prime}$ cut across prepositional and postpositional languages, in a way quite different from Kayne (1994). Complementizers are interestingly similar to adpositions (and deserve more space than I have given them here.) $)^{62}$

60 If quotative complementizers are verbs, they do not fall under this discussion.

61 That Japanese embedded verbs are non-finite/participial is not obvious, but neither is it obvious that they are finite, I think.

Note in particular that Japanese polite -mas- is by and large limited to nonembedded contexts, as pointed out by Harada $(1976: 503,544)$ and confirmed to me in discussion with Keiko Muromatsu. Thus -mas- is plausibly like English modals in being an auxiliary restricted to finite contexts. The even more restricted distribution of -mas- (compared with English modals) may then be due to the fact that embeddings in Japanese are by and large non-finite.

The similar distribution of polite -des- may suggest that both -mas- and -des- are bimorphemic, with the second morpheme being $-s-$. The restriction to finite contexts may then be a property of this $-s-$, recalling the (usually) polite do of Do sit down.

62 Cf. Emonds (1985). 


\section{REFERENCES}

Aboh, Enoch O. (1999) From the Syntax of Gungbe to the Grammar of Gbe, Editions à la Carte SA, Sierre, Switzerland.

Appleyard, David (1995) Colloquial Amharic: A Complete Language Course, Routledge, London.

Baker, Mark C. (1988) Incorporation: A Theory of Grammatical Function Changing, University of Chicago Press, Chicago.

Barbiers, Sjef (2000a) "The Right Periphery in SOV Languages: English and Dutch," The Derivation of $V O$ and $O V$, ed. by P. Svenonius, John Benjamins, Amsterdam.

Barbiers, Sjef (2000b) "Intermediate Landing Sites," GLOT 4-7, 15.

Bayer, Josef (1993) "Zum in Bavarian and Scrambling," Dialektsyntax (Sonderheft 5 der Linguistischen Berichte), ed. by Werner Abraham and Josef Bayer, 50-70.

Bayer, Josef (2001) "Two Grammars in One: Sentential Complements and Complementizers in Bengali and Other South Asian Languages," The Yearbook of South Asian Languages: Tokyo Symposium on South Asian Languages - Contact, Convergence and Typology, ed. by P. Bhaskarorao and K. V. Subbarao, 11-36, Sage Publications, New Dehli.

Branch, Michael (1987) "Finnish," The World's Major Languages, ed. by B. Comrie, 593-617, Oxford University Press, New York.

Brody, Michael (1990) "Remarks on the Order of Elements in the Hungarian Focus Field," Approaches to Hungarian. Volume Three. Structures and Arguments, ed. by I. Kenesei, 95-121, Jate Szeged.

Buell, Leston (2002) "Swahili Amba-less Relatives without Head Movement," UCLA Working Papers in Linguistics, 8 (Papers in African Linguistics), 86-106.

Carstens, Vicki (2002) "Antisymmetry and Word Order in Serial Constructions," Language 78, 3-50.

Chomsky, Noam (1995) The Minimalist Program, MIT Press, Cambridge, MA.

Chomsky, Noam (2000) "Minimalist Inquiries: The Framework," Step by Step: Essays on Minimalist Syntax in Honor of Howard Lasnik, ed. by Roger Martin, David Michaels and Juan Uriagereka, 89-155, MIT Press, Cambridge, MA.

Chomsky, Noam (2001a) "Derivation by Phase," Ken Hale. A Life in Language, ed. by Michael Kenstowicz, 1-52, MIT Press, Cambridge, MA.

Chomsky, Noam (2001b) "Beyond Explanatory Adequacy," ms., MIT.

Chung, Sandra and James McCloskey (1983) "On the Interpretation of Certain Island Facts in GPSG," Linguistic Inquiry 14, 704-713.

Cinque, Guglielmo (1990) Types of $A^{\prime}$-Dependencies, MIT Press, Cambridge, MA.

Cinque, Guglielmo (1996) "The Antisymmetric Programme: Theoretical and Typological Implications," Journal of Linguistics 32, 447-464. 
Cinque, Guglielmo (1999) Adverbs and Functional Heads: A Cross-Linguistic Perspective, Oxford University Press, New York.

Cinque, Guglielmo (2002) "Complement and Adverbial PPs: Implications for Clause Structure," paper presented at GLOW 2002, Amsterdam

Creissels, Denis (2000) "Typology," African Languages: An Introduction, ed. by B. Heine and D. Nurse, 232-258, Cambridge University Press, Cambridge.

Crum, Beverly and Jon Dayley (1993) Western Shoshoni Grammar (Occasional Papers and Monographs in Cultural Anthropology and Linguistics. Volume No. 1), Boise State University.

Dahl, Östen (1979) “Typology of Sentence Negation," Linguistics 17, 79-106.

Dejean, Yves (1993) "Manifestations en Créole Haïtien du Principe d'adjacence Stricte."

Den Besten, Hans and Gert Webelhuth (1990) "Stranding," Scrambling and Barriers, ed. by G. Grewendorf and W. Sternefeld, 77-92, Academic Press, Amsterdam.

Den Dikken, Marcel (1995) "Extraposition as Intraposition, and the Syntax of English Tag Questions," ms., Vrije Universiteit Amsterdam/HIL.

Déprez, Viviane (1998) "Semantic Effects of Agreement: The Case of French Participle Agreement," Probus 10, 1-67.

Diesing, Molly (1992) Indefinites, MIT Press, Cambridge, MA.

Dryer, Matthew S. (1988) "Universals of Negative Position," Studies in Syntactic Typology, ed. by Michael Hammond, Edith Moravcsik and J. Wirth, 93-124, John Benjamins, Amsterdam.

Dryer, Matthew S. (1991) "SVO Languages and the OV/VO Typology," Journal of Linguistics 27, 443-482.

Dryer, Matthew S. (1992) "The Greenbergian Word Order Correlations," Language 68, 81-138.

Dryer, Matthew S. (1996) "Word Order Typology," Handbook on Syntax, Vol. 2, ed. by Joachim Jacobs, 1050-1065, Walter de Gruyter, Berlin.

Emonds, Joseph E. (1985) A Unified Theory of Syntactic Categories, Foris, Dordrecht.

Fabb, Nigel (1984) Syntactic Affixation, Doctoral dissertation, MIT.

Fiengo, Robert and James Higginbotham (1981) "Opacity in NP," Linguistic Analysis 7, 395-421.

Fukui, Naoki (1986) A Theory of Category Projection and Its Applications, Doctoral dissertation, MIT.

Gragg, Gene B. (1972) "Sumerian and Selected Afro-Asiatic Languages," The Chicago Which Hunt. Papers from the Relative Clause Festival, ed. by Paul M.Peranteau et al., 153-168, Chicago Linguistic Society, Chicago.

Greenberg, Joseph H. (1966) "Some Universals of Grammar with Particular Reference to the Order of Meaningful Elements," Universals of Language, Second Edition, ed. by Joseph H. Greenberg, MIT Press, Cambridge, MA. 
Haddican, William (2001) "Basque Functional Heads," ms., New York University.

Haddican, William (2002) "Basque Functional Heads," ms., New York University.

Haegeman, Liliane (2000) "Remnant Movement and OV Order," The Derivation of $O V$ and $V O$, ed. by Peter Svenonius, 69-96, John Benjamins, Amsterdam.

Haegeman, Liliane (2001) "Antisymmetry and Verb-final Order in West Flemish,” The Journal of Comparative Germanic linguistics 3, 207-232.

Haegeman, Liliane (to appear) "West Flemish Negation and the Derivation of SOV Order in West Germanic," Nordic Journal of Linguistics (Special issue on negation).

Harada, Shin-Iti (1976) "Honorifics," Japanese Generative Grammar. Syntax and Semantics. Volume 5, ed. by M. Shibatani, 499-561, Academic Press, New York.

Hawkins, John A. (1990) "A Parsing Theory of Word Order Universals," Linguistic Inquiry 21, 223-261.

Henry, Alison (1995) Belfast English and Standard English. Dialect Variation and Parameter Setting, Oxford University Press, New York.

Hoekstra, Teun (1999) "Parallels between Nominal and Verbal Projections," Specifiers. Minimalist Approaches, ed. by David Adger, Susan Pintzuk, Bernadette Plunkett and George Tsoulas, 163-187, Oxford University Press, Oxford.

Huang, C.-T. James (1994) "More on Chinese Word Order and Parametric Theory," Syntactic Theory and First Language Acquisition: Crosslinguistic Perspectives - Volume 1: Phrase Structure, ed. by Barbara Lust, John Whitman and Jaklin Kornfilt, 15-35, Lawrence Erlbaum Associates, Hillsdale, NJ.

Hyman, Larry M. and Daniel J. Magaji (1970) Essentials of Gwari Grammar, Institute of African Studies, University of Ibadan.

Jayaseelan, Karattuparambil A. (2001) "IP-internal Topic and Focus Phrases," Studia Linguistica 55, 39-75.

Jeanne, Laverne M. (1978) Aspects of Hopi Grammar, Doctoral dissertation, MIT.

Jonas, Dianne and Jonathan D. Bobaljik (1993) "Specs for Subjects: The Role of TP in Icelandic," MIT Working Papers in Linguistics \#18: Papers on Case \& Agreement I, ed. by Jonatham D. Bobaljik and Colin Phillips.

Julien, Marit (2002) Syntactic Heads and Word Formation, Oxford University Press, New York.

Julien, Marit (2003) "Word Order Type and Syntactic Structure," Linguistic Variation Yearbook 1, ed. by Johan Rooryck and Pierre Pica, 19-61, John Benjamins, Amsterdam.

Kayne, Richard S. (1979) "Rightward NP Movement in French and English," Linguistic Inquiry 10, 710-719. 
Kayne, Richard S. (1981a) "Two Notes on the NIC," Theory of Markedness in Generative Grammar. Proceedings of the 1979 GLOW Conference, ed. by Adriana Belletti, Luciana Brandi and Luigi Rizzi, 317-346, Scuola Normale Superiore, Pisa (reprinted in Kayne (1984)).

Kayne, Richard S. (1981b) "On Certain Differences between French and English," Linguistic Inquiry 12, 349-371 (reprinted in Kayne (1984)).

Kayne, Richard S. (1982) "Predicates and Arguments, Verbs and Nouns," paper presented at the GLOW Conference, GLOW Newsletter 8, 24.

Kayne, Richard S. (1984) Connectedness and Binary Branching, Foris, Dordrecht.

Kayne, Richard S. (1994) The Antisymmetry of Syntax, MIT Press, Cambridge, MA.

Kayne, Richard S. (1998) “Overt vs. Covert Movement," Syntax 1, 128-191 (reprinted in Kayne (2000b)).

Kayne, Richard S. (2000a) "On the Left Edge in UG. A Reply to McCloskey," Syntax 3, 44-51.

Kayne, Richard S. (2000b) Parameters and Universals, Oxford University Press, New York.

Kayne, Richard S. (to appear - a) "On the Syntax of Quantity in English."

Kayne, Richard S. (to appear-b) "On Some Prepositions That Look DPinternal: English of and French de," Catalan Journal of Linguistics.

Kayne, Richard S. (to appear - c) "Prepositions as Probes."

Kayne, Richard S. and Jean-Yves Pollock (2001) "New Thoughts on Stylistic Inversion" Inversion in Romance, ed. by A. Hulk and Jean-Yves Pollock, Oxford University Press, New York.

Keenan, Edward L. (1985) "Relative Clauses," Language Typology and Syntactic Description, Volume II, Complex Constructions, ed. by Timothy Shopen, 141-170, Cambridge University Press, Cambridge.

Koopman, Hilda (1992) "On the Absence of Case Chains in Bambara," Natural Language and Linguistic Theory 10, 555-594.

Koopman, Hilda (to appear) "Inside the 'Noun' in Maasai."

Koopman, Hilda and Dominique Sportiche (1989) "Pronouns, Logical Variables and Logophoricity in Abe," Linguistic Inquiry 20, 555-589.

Koopman, Hilda and Anna Szabolcsi (2000) Verbal Complexes, MIT Press, Cambridge, MA.

Kornfilt, Jaklin (1995) "Some Typological Properties of Complementation in Turkish," ms., Syracuse University.

Kornfilt, Jaklin (2000) "Locating Relative Agreement in Turkish and Turkic," Studies on Turkish and Turkic Languages, ed. by A. Goksel and C. Kerslake, 189-196, Harrassowitz Verlag, Wiesbaden.

Koster, Jan (1978) "Why Subject Sentences Don't Exist," Recent Transformational Studies in European Languages, ed. by Samuel J. Keyser, 53-64, MIT Press, Cambridge, MA.

Kroch, Anthony S. (2001) "Syntactic Change," The Handbook of Contempo- 
rary Syntactic Theory, ed. by Mark Baltin and Colin Collins, 699-729, Blackwell, Malden, MA.

Laka, Itziar (1990) Negation in Syntax: On the Nature of Functional Categories and Projections, Doctoral dissertation, MIT.

Larson, Richard K. (1988) "On the Double Object Construction," Linguistic Inquiry 19, 335-391.

Larson, Richard K. (1990) "Double Objects Revisited: Reply to Jackendoff," Linguistic Inquiry 21, 589-632.

Lecarme, Jacqueline (1991) "Focus en Somali: Syntaxe et Interpretation," Linguistique Africaine 7, 33-63.

Lecarme, Jacqueline (1999) "Focus in Somali," The Grammar of Focus (Linguistik Aktuell / Linguistics Today 24), ed. by G. Rebuschi and L. Tuller, 275-309, John Benjamins, Amsterdam.

Legate, Julie A. (to appear) "Some Interface Properties of the Phase."

Martin, Samuel E. (1992) Essential Japanese: An Introduction to the Standard Colloquial Language, Tuttle, Boston.

McCloskey, James (1984) "Raising, Subcategorization, and Selection in Modern Irish," Natural Language and Linguistic Theory 1, 441-485.

McCloskey, James and Peter Sells (1988) "Control and A-Chains in Modern Irish," Natural Language and Linguistic Theory 6, 143-189.

Miyagawa, Shigeru (1997) “Against Optional Scrambling," Linguistic Inquiry $28,1-25$.

Murasugi, Keiko S. (2000) "Japanese Complex Noun Phrases and the Antisymmetry Theory," Step by Step: Essays on Minimalist Syntax in Honor of Howard Lasnik, ed. by Roger Martin, David Michaels and Juan Uriagereka, 211-234, MIT Press, Cambridge, MA.

Myers, Scott P. (1987) Tone and the Structure of Words in Shona, Doctoral dissertation, University of Massachusetts, Amherst.

Ngonyani, Deogratias S. (1996) The Morphosyntax of Applicatives, Doctoral dissertation, UCLA, Los Angeles.

Nilsen, Øystein (2003) Eliminating Positions: The Syntax and Semantics of Sentence Modification, Doctoral dissertation, University of Utrecht.

Ogawa, Yoshiki (2001) A Unified Theory of Verbal and Nominal Projections, Oxford University Press, New York.

Pearson, Matthew (1997) "Feature Inheritance, Head Movement, and Pied Piping: Deriving Head-Final Structures," ms., UCLA (paper presented at the Japanese Syntax in a Comparative Context Workshop, Cornell University, July, 1997).

Pearson, M. (2000) "Two Types of VO Languages," The Derivation of VO and $O V$, ed. by Peter Svenonius, John Benjamins, Amsterdam.

Pesetsky, David (1995) Zero Syntax, MIT Press, Cambridge, MA.

Poletto, Cecilia (2000) The Higher Functional Field in the Northern Italian Dialects, Oxford University Press, New York.

Pollock, Jean-Yves (1985) "On Case and the Syntax of Infinitives in French," 
Grammatical Representation, ed. by Jacqueline Guéron, Hans-Georg Obenauer and Jean-Yves Pollock, 293-326, Foris, Dordrecht.

Pollock, Jean-Yves (1989) "Verb Movement, Universal Grammar, and the Structure of IP," Linguistic Inquiry 20, 365-424.

Raposo, Eduardo (1987) "Case Theory and Infl-to-Comp: The Inflected Infinitive in European Portuguese," Linguistic Inquiry 18, 85-109.

Reuland, Eric (1983) "Governing -ing," Linguistic Inquiry 14, 101-136.

Richards, Norvin (1997) What Moves Where When in Which Language?, Doctoral dissertation, MIT.

Riemsdijk, Henk van (1983) "The Case of German Adjectives," Linguistic Categories: Auxiliaries and Related Puzzles. Volume One: Categories, ed. by F. Heny and B. Richards, 223-252, D. Reidel, Dordrecht.

Riemsdijk, Henk van (1992) "Complements, Adjuncts and Adjacency in Phrase Structure," Hommages à Nicolas Ruwet, ed. by L. Tasmowski and Anne Zribi-Hertz, 498-512, Communication \& Cognition, Ghent.

Riemsdijk, Henk van and M. A. C. Huybregts (to appear) "Location and Locality."

Rizzi, Luigi (1997) "The Fine Structure of the Left Periphery," Elements of Grammar. Handbook of Generative Syntax, ed. by Liliane Haegeman, 281-337, Kluwer, Dordrecht.

Rosenbaum, Peter S. (1967) The Grammar of English Predicate Complement Constructions, MIT Press, Cambridge, MA.

Saito, Mamoru and Naoki Fukui (1998) "Order in Phrase Structure and Movement," Linguistic Inquiry 29, 439-474.

Sigler, Michelle (1997) Specificity and Agreement in Standard Western Armenian, Doctoral dissertation, MIT.

Simpson, Andrew and Zoe Wu (2002a) "IP-raising, Tone Sandhi and the Creation of Particles: Evidence for Cyclic Spell-Out," Journal of East Asian Linguistics 11, 67-99.

Simpson, Andrew and Zoe Wu (2002b) "Agreement, Shells and Focus," Language 77, 287-313.

Smits, Rik (1989) Eurogrammar: The Relative and Cleft Constructions of the Germanic and Romance Languages, Doctoral dissertation, University of Tilburg.

Sportiche, Dominique (2002) "Movement Types and Triggers," GLOW Newsletter 48, 116-117.

Stowell, Timothy A. (1981) Origins of Phrase Structure, Doctoral dissertation, MIT.

Svenonius, Peter (1992) "The Extended Projection of N: Identifying the Head of the Noun Phrase," Working Papers in Scandinavian Syntax 49, 95-121.

Szabolcsi, Anna (1983) "The Possessor that Ran Away from Home," The Linguistic Review 3, 89-102.

Szabolcsi, Anna (1994) "The Noun Phrase," Syntax and Semantics 27: The Syntactic Structure of Hungarian, ed. by Ferenc Kiefer and Katalin E. Kiss, 
179-274, Academic Press, San Diego.

Taljaard, P. C., J. N. Khumalo and S. E. Bosch (1991) Handbook of Siswati, J. L. van Schaik, Pretoria.

Tamrazian, Armine (1994) The Syntax of Armenian: Chains and the Auxiliary, Doctoral dissertation, University College London.

Tang, Sze-Wing (1998) Parameterization of Features in Syntax, Doctoral dissertation, University of California at Irvine.

Taraldsen, Knut Tarald (1981) "The Theoretical Interpretation of a Class of 'Marked' Extractions," Theory of Markedness in Generative Grammar, Proceedings of the 1979 GLOW Conference, ed. by Adriana Belletti, Luciana Brandi and Luigi Rizzi, 475-516, Scuola Normale Superiore, Pisa.

Thráinsson, Höskuldur (1994) "Icelandic," The Germanic Languages, ed. by Ekkehard König and Johan van der Auwera, 142-189, Routledge, London.

Travis, Lisa (1989) "Parameters of Phrase Structure," Alternative Conceptions of Phrase Structure, ed. by Anthony S. Kroch and Mark R. Baltin, 263-279, University of Chicago Press.

Vilkuna, Maria (1998) "Word Order in European Uralic," Constituent Order in the Languages of Europe, ed. by A. Siewierska, Mouton de Gruyter, Berlin.

Whitman, John (2001) "Kayne 1994: p. 143, fn. 3," The Minimalist Parameter, ed. by G. Alexandrova and O. Artunova, 77-100, John Benjamins, Amsterdam.

Whitman, John (to appear) "Preverbal Elements in Korean and Japanese," Handbook of Comparative Syntax, ed. by Guglielmo Cinque and Richard Kayne, Oxford University Press, New York.

Williamson, Kay and Roger Blench (2000) "Niger-Congo," African Languages: An Introduction, ed. by B. Heine and D. Nurse, Cambridge University Press, Cambridge.

Zepeda, Ofelia (1983) A Papago Grammar, University of Arizona Press, Tucson.

470 West End Ave.

New York, NY 10024

USA

e-mail: richard.kayne@nyu.edu 